\title{
Effects of Different Plasma Nitrided Layers on the Tribological Performance of DLC Coatings
}

\author{
Pedro Henrique Teshima Shioga ${ }^{a *}$, Cristiano Binder ${ }^{a}$, Gisele Hammes ${ }^{a}$, Aloisio Nelmo Klein ${ }^{a}$, Jose \\ Daniel Biasoli de Mello ${ }^{a}$ \\ ${ }^{a}$ Laboratório de Materiais - Labmat, Departamento de Engenharia Mecânica, Universidade Federal de
Santa Catarina - UFSC, Rua Delfino Conti, s/n, Florianópolis, SC, Brazil
}

Received: August 10, 2015; Revised: July 19, 2016; Accepted: August 11, 2016

\begin{abstract}
When multifunctional surface engineering processes that combine purpose-oriented phases are applied to soft substrates, a combination of high wear resistance, high load support and low coefficients of friction can be achieved. In this study, the effects of different nitrided layers on the tribological behaviour of a diamond-like carbon (DLC) film deposited on a SAE 1040 steel were investigated. The nitriding was carried out under different temperatures and gas mixtures to create three distinct nitrided layers: two compound layers with predominant $\varepsilon$ and $\gamma^{\prime}$ phases and a diffusion layer. All of the surfaces were then coated with DLC deposited via plasma-enhanced chemical vapour deposition (PECVD). The tribological tests indicated that the best performance was achieved for a specific combination of hardness, surface roughness and nitride type. The best load-bearing capacity between the DLC coating and the soft substrate was achieved when the nitrided layer was primarily a diffusion layer.
\end{abstract}

Keywords: DLC, Nitriding, Roughness, Friction, Adhesion

\section{Introduction}

Diamond-like carbon (DLC) encompasses a family of coatings with widespread use in tribological applications due to their low coefficients of friction in metal-DLC pairs (usually $0.1<\mu<0.2$, but values as low as 0.01 have been reported $)^{1-3}$, which are associated with extremely low wear rates $\left(10^{-9}-10^{-10} \mathrm{~mm}^{3} / \mathrm{Nm}\right)^{3,4}$.

Hard solid lubricant coatings have found success in many applications, particularly those involving pure elements such as silicon and advanced materials ${ }^{5-8}$. Other systems have used relatively hard substrates, such as hardened steels ${ }^{9}$; however large-volume production industries utilise soft, simple and inexpensive materials as substrates for DLC coatings, which require multifunctional surfaces for mechanical support and chemical adhesion.

One solution involves progressively increasing the surface hardness and creating a mechanical support by plasma nitriding, a diffusive thermochemical treatment that increases the surface hardness of steels and metallic alloys $^{10,11}$. In contrast to other surface treatments such as gas nitriding, salt bath nitriding, carbonitriding, and nitrocarburising ${ }^{12-15}$, in plasma nitriding temperature is not dependent of a conventional heat source. Plasma energy is the heat source and process temperature can be adjusted with plasma voltage and pressure in addition to an external heat source. Thus, producing minimum dimensional distortions in the treated parts, which are normally caused by stress relief if temperatures of up to $600^{\circ} \mathrm{C}$ are used ${ }^{10}$. Therefore, plasma nitriding is an interesting technique used to produce multi-layered coatings for components employed in highprecision applications. Moreover, this process generates little waste, requires few consumables, is easy to control and compatible with the levels required by industry ${ }^{10,16}$ but mostly the same equipment can be used to carry out nitriding and DLC-coating ${ }^{17-19}$

The resulting coating is composed of two main layers: an external compound layer with the highest hardness values and a diffusion layer with a hardness that decreases toward the core of the material. During plasma nitriding, this nitrided layer structure is achieved by accelerating nitrogen ions against the sample surface, cleaning the surface, heating the workpiece, and providing active nitrogen that diffuses into the matrix ${ }^{20,21}$. Unfortunately, this bombardment also modifies the topographical characteristics of the specimen ${ }^{10}$, increasing the roughness to the micrometre range $\mathrm{e}^{22,23}$ and directly affecting the mechanical support of DLC $C^{8,24}$.

Depending on the control variables applied in this process, particularly the temperature and gas mixture, different nitride phases with distinct characteristics can be stabilised $^{21}$. Previous studies have reported surfaces with different hardness profiles and case depths for different gas mixtures ${ }^{23}$. Another study showed that nitriding significantly changes the surface roughness relying on processing parameters. The initial roughness can also affect the case depths of the nitrided layers ${ }^{25}$.

* e-mail: pedro.shioga@labmat.ufsc.br 
Due to the multifunctional nature of the surface, all of these factors can significantly affect the adhesion of DLC, which in turn affects tribological performance.

Techniques based on indentation tests, which are used to assess adhesion, particularly the German standard VDI3198 26,27 , are popular due to their simplicity and ease of use. In these methods, the surface is indented under standardised parameters, resulting in film failure. The failure is characterised through six qualitative patterns: HF1 to HF6. However, four important issues have been identified when using this method:

- There is a strong dependence on user interpretation, affecting the characterisation process when the failure characteristics are similar or when different people are performing the classification;

- Because only six patterns are available, the standard categorises different forms and intensities of delamination equally;

- $\quad$ Beyond the maximum classification HF6, every indentation with a large delamination area is classified as the same pattern;

- The results of film cracking and delamination vary over time after introducing the indentation, but the standard does not define when to perform the analysis.

Therefore, we developed this technique further, yielding an enhanced method based on the VDI3198 standard, and image analysis was proposed for assessing delamination.

In this study, the relationship between the nitriding parameters, surface roughness, coating adhesion and tribological performance were assessed. In particular, multipurpose coatings (different nitrided layers coated with DLC) were characterised by 3D surface topography analysis, indentation tests and reciprocating sliding tests.

\section{Materials and methods}

Three nitrided layers with different characteristics were produced: one compound layer with a predominant $\varepsilon$ phase, one compound layer with a predominant $\gamma^{\prime}$ phase and one diffusion layer. These surfaces were then coated with the same DLC material. These multifunctional surfaces are referred to as $\varepsilon, \gamma$ ' and diffusion. Figure 1 shows the processes and characterisation techniques used in this work.

The multipurpose coatings were deposited on SAE1040 carbon steel, which is a class of material commonly used in the mechanical industry. The samples were obtained by cutting a bar of SAE1040 carbon steel; one of the flat faces was ground and mirror polished to an $\mathrm{Sq}$ value $<0.05 \mu \mathrm{m}$. The samples were subsequently nitrided in a hot wall plasma reactor under three different processing conditions. These conditions were developed based on a previous study ${ }^{11}$ and are presented in Table 1. A plasma was produced using electrical discharge in the

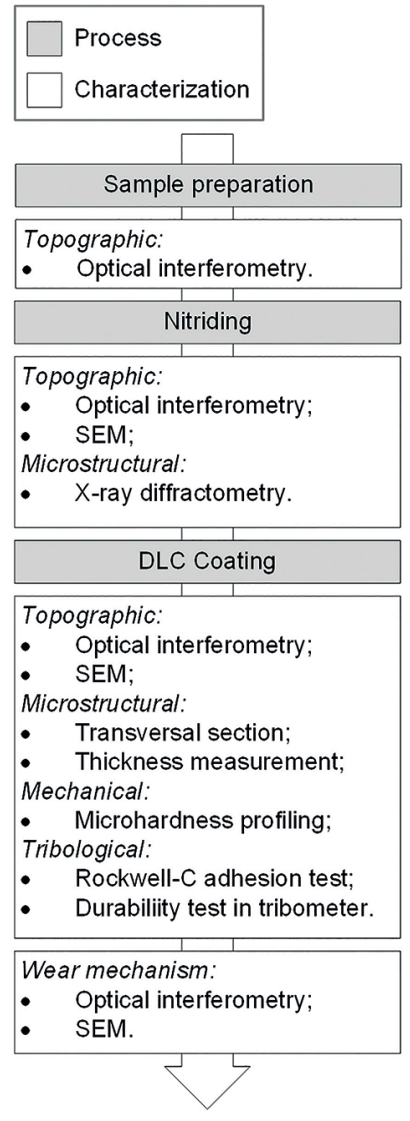

Figure 1: Experimental organogram containing processing and characterization techniques organized in chronological sequencing..

luminescent abnormal regime with a voltage of $-500 \mathrm{~V}$ applied to the samples via a square-wave signal with a frequency of 4 $\mathrm{kHz}$ and a duty cycle of $62,5 \%$.

The DLC layers were obtained via PECVD in two steps: one involving a high silicon content for adhesion ${ }^{28,29}$ and one involving only a hydrocarbon precursor.

The nitride phases were characterised using an X-ray diffractometer with $\mathrm{Cu} \mathrm{K} \alpha(\lambda=1.5418 \AA)$ radiation and a Bragg-Bretano geometry $(40 \mathrm{kV}-30 \mathrm{~mA})$.

The evolution of the samples' surface topography was monitored using optical white-light interferometry. $3 \mathrm{D}$ images were obtained using sample sizes of $640 \times 480$ points with a lateral resolution of $0.28 \mu \mathrm{m}$ and a vertical resolution of $0.1 \mathrm{~nm}$. The surfaces were analysed using the Mountains Map ${ }^{\circledR}$ software. After form removal, the waviness was subtracted using a $25 \mu \mathrm{m}$ cut-off, and the surface roughness parameters were obtained. To complement the surface analysis, SEM images of the surfaces were obtained.

The adhesion of the coatings was determined using an enhanced technique based on the German standard VDI3198, causing the films to fail when using a standardised Rockwell-C indenter (diamond cone; $120^{\circ}$; tip radius of $0.2 \mathrm{~mm}$ ) and a normal force $(1474 \mathrm{~N})$. 
Table 1: Nitriding parameters

\begin{tabular}{lcccc}
\hline Temperature $\left({ }^{\circ} \mathrm{C}\right)$ & Pressure (Torr) & Time $(\mathrm{h})$ & Gas mixture $(\%)$ & Expected phase \\
\hline 550 & 2 & 1.5 & $90 \mathrm{~N} 2-9 \mathrm{H} 2-1 \mathrm{CH} 4$ & $\varepsilon$ \\
570 & 2 & 4.0 & $20 \mathrm{~N} 2-80 \mathrm{H} 2$ & $\gamma^{\prime}$ \\
480 & 2 & 1.5 & $5 \mathrm{~N} 2-95 \mathrm{H} 2$ & Diffusion layer \\
\hline
\end{tabular}

The tribological behaviour of the multipurpose coatings (DLC+nitrided layer) was evaluated through a durability test using the method presented by de Mello and Binder ${ }^{30}$ In this method, the sample surface is subjected to reciprocating movement under an increasing normal load until failure and with a consequent increase in friction. A tribometer with reciprocating movement $(2 \mathrm{~Hz})$ was used, and the initial normal load $(7 \mathrm{~N})$ was increased in intervals of 7 $\mathrm{N}$; a counter body, specifically a sphere measuring $3 \mathrm{~mm}$ in diameter made of $\mathrm{Si}_{3} \mathrm{~N}_{4}$, in an atmosphere composed of ambient air $\left(25^{\circ} \mathrm{C}\right.$ and $60 \%$ relative humidity) were used.

\section{Results and Discussion}

The processing parameters presented in Table 1 produced three types of surfaces, as demonstrated by the transversal sections of the layers depicted in Figure 2, where layer thickness was measured. Under the first two conditions, a homogeneous compound layer was formed. The depth of the compound on the $\varepsilon$ layer was approximately $6.5 \mu \mathrm{m}$, whereas that on the $\gamma$ ' layer was approximately $4.5 \mu \mathrm{m}$. Noly, the growth rate of the $\varepsilon$ layer was considerably higher than that of the $\gamma$ ' layer; even after increasing the treatment time for the $\gamma$ ' layer by more than 2.5 times the original treatment time, the formed layer was $30 \%$ thinner than the $\varepsilon$ layer. On the diffusion layer, small non-continuous compound phase formed on the surface. The DLC thickness was also assessed under all three conditions, which all produced $1.8 \mu \mathrm{m}$ thick DLC.

Each of the surfaces was assessed in an X-ray diffractometer, revealing that the desired nitride phases were obtained, as shown in the diffractograms presented in Figure 3. Layer (a) of the figure exhibited a combination of the $\varepsilon$ and $\gamma^{\prime}$ phases, with a predominance of the former. Layer (b) contained only the $\gamma^{\prime}$ phase. Layer (c) presented $\alpha$-ferrite and $\gamma$ ' peaks due to the presence of small non-continuous $\gamma^{\prime}$ nitride formations on the surface.

The surface hardening caused by nitriding was analysed using the profiles created via Vickers micro-indentation at $50 \mathrm{~g}$ load, first indentation was measured from the plan view and further measured from the cross section with $10 \mu \mathrm{m}$ space in between. The two compound layers presented the highest hardness ( $880 \mathrm{HV})$, which rapidly decayed within $20 \mu \mathrm{m}$ to match the core hardness ( $300 \mathrm{HV})$. The diffusion layer had a surface hardness of $380 \mathrm{HV}$, also matching the core hardness within $20 \mu \mathrm{m}$.

The surface development was assessed through optical interferometry and SEM images shown in Figure 4. At first glance, it appears that the $\varepsilon$ and $\gamma^{\prime}$ conditions generated larger modifications, particularly the $\gamma^{\prime}$ conditions. The formation of peaks over a plateau can be observed on top of the surface generated by the diffusion conditions. When comparing the surfaces before and after DLC coating, the DLC appears to mimic the previous topography, except for that of the $\gamma$ ' layer; the roughness over the $\gamma$ ' layer appears to have increased primarily through the formation of valleys.

These SEM images show that the gas mixture ratios clearly affected the resulting surface characteristics directly. The conditions for growing only a diffusion layer are the ones that produced the smallest modifications, followed by the conditions for the $\varepsilon$ layer and then the $\gamma$ ' layer. Under the $\gamma$ ' conditions, several electronic charging dots can be observed, in contrast to the observations made for the other two sets of conditions. This difference is primarily attributed to the longer treatment time; according to Mason ${ }^{31}$, $90 \%$ of pulverised atoms return to the cathode after being backscattered, creating the structures revealed by SEM. Comparing the images of the coated surfaces images to the nitrided ones reveals that the DLC copied the topography of

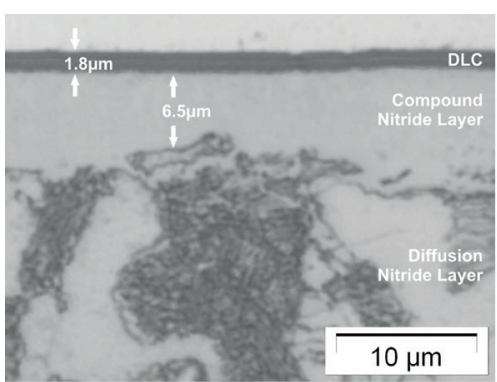

(a)

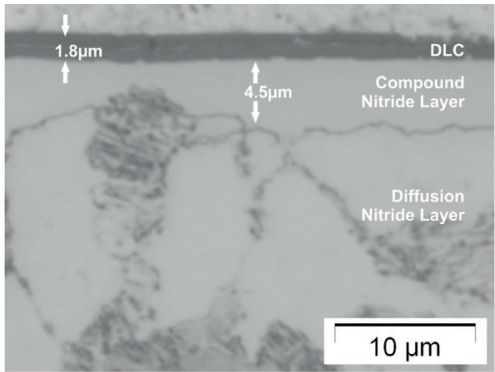

(b)

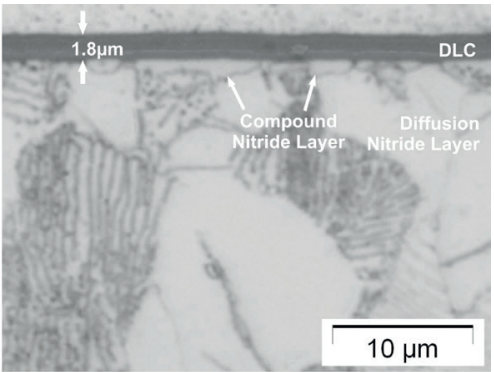

(c)

Figure 2: Transversal sections of: (a) $\varepsilon$-phase compound layer; (b) $\gamma^{\prime}$-phase compound layer; and (c) diffusion layer, indicating layers and thicknesses. 


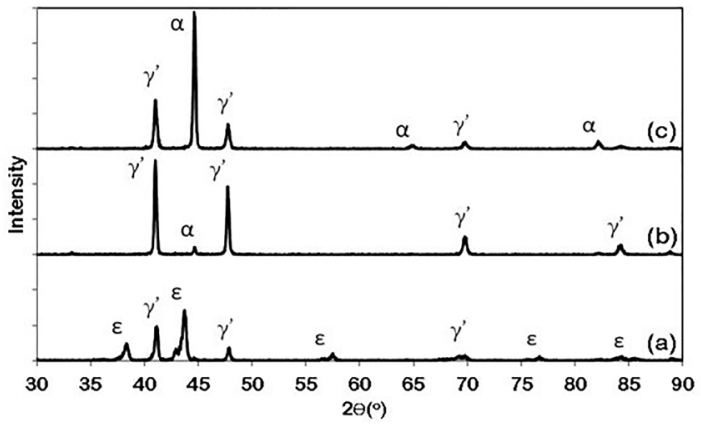

Figure 3: X-ray diffractograms of: (a) $\varepsilon$-phase predominant surface; (b) $\gamma$ '-phase surface; and (c) diffusion surface with small noncontinuous $\gamma^{\prime}$ nitride formations.

the previous surface under the $\varepsilon$ and diffusion conditions. In the SEM image of the film produced under the $\gamma$ ' conditions, the heterogeneous formation of the coating can be observed; regions with densified film and bad formation where the previous surface occurred are apparent. Therefore, the topography and composition of the $\gamma$ ' layer significantly altered the deposition conditions of the DLC.

The surface root mean square roughness parameter (Sq) proves the validity of these initial observations of the development of the surfaces, as shown in Figure 5. The data are organised based on the conditions and processing steps: polished surface; nitrided surface; DLC-coated surface. The nitriding process increased the roughness by at least one order of magnitude under all conditions. As observed in the projections, the $\varepsilon$ and $\gamma^{\prime}$ conditions increased the roughness by a factor of approximately two relative to that achieved under the diffusion conditions. After coating with DLC, the roughness of the $\varepsilon$ and diffusion layers remained unmodified, unlike that achieved under the $\gamma^{\prime}$ conditions. Under the $\gamma^{\prime}$ conditions, the mean Sq values increased.

The adhesion of the DLC film over the nitrided layers was characterised using a more refined version of the German standard VDI 3198. This method was developed as a routine in an image analysis software program and was used to quantify the area covered by film delamination and, subsequently, to compare the surfaces directly. The colours of the film and the substrate where the film detached could be differentiated using a contrast tool; afterwards, the delamination area could be calculated based on the pixel area before being converted to $\mathrm{mm}^{2}$ after subtracting the indentation area. To assess how the delamination varied over time, the same indentation was analysed at different times, as shown in Figure 6. The delaminated area varied dramatically over the first hour after indentation, growing slowly over the hours that followed. The minimum period was defined as 24 hours after indentation to measure the failure area when the variation did not exceed $1 \%$. Samples within this period were stored in medium vacuum and room temperature, around $20^{\circ} \mathrm{C}$.

Figure 7 presents the results of the adhesion tests under all three conditions; most of the delamination occurred on the indentation perimeter where the stress was higher ${ }^{32}$. Figure 8 shows the delamination areas. The DLC layers on top of the compound $\varepsilon$ and $\gamma$ ' layers exhibited the lowest extent of delamination, whereas the extent of delamination on the diffusion layer was almost twice that observed for the other layers.

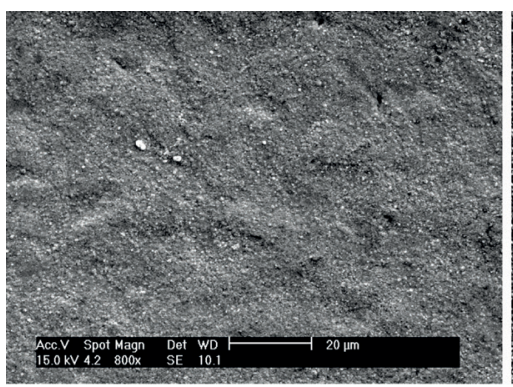

(a)

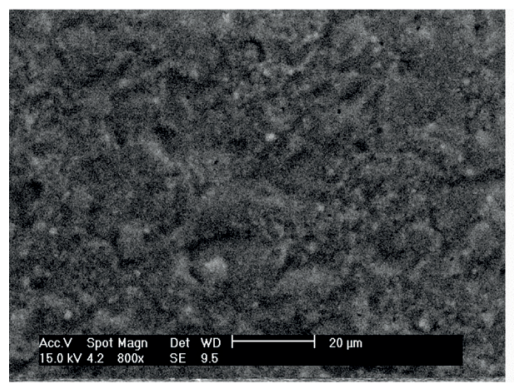

(d)

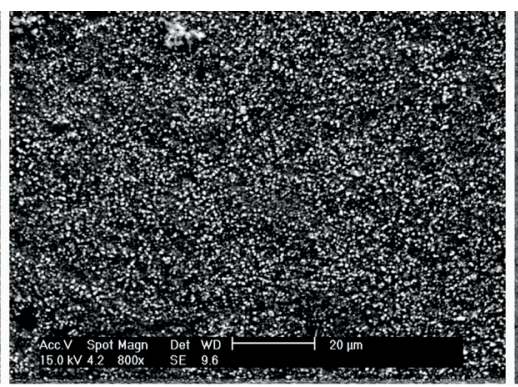

(b)

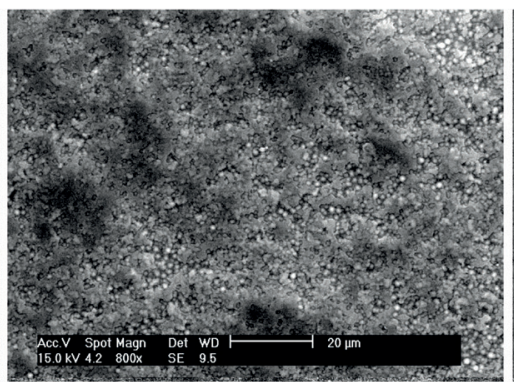

(e)

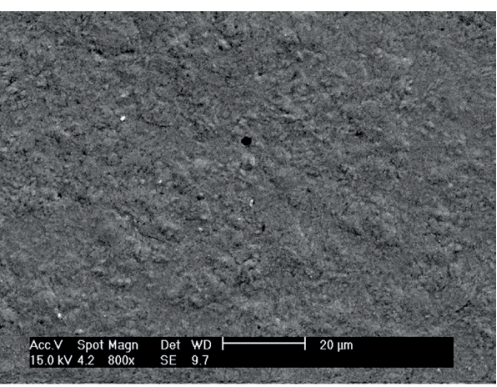

(c)

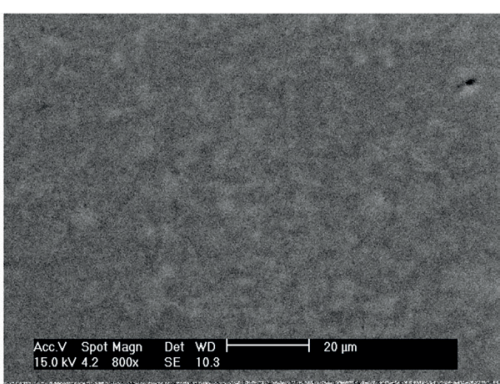

(f)

Figure 4: Top-down SEM images of nitrided and coated surfaces: (a) $\varepsilon$-phase surface; (b) $\gamma$ '-phase surface; (c) diffusion surface; (d) coated $\varepsilon$-phase surface; (e) coated $\gamma^{\prime}$-phase surface; (f) coated diffusion surface. 


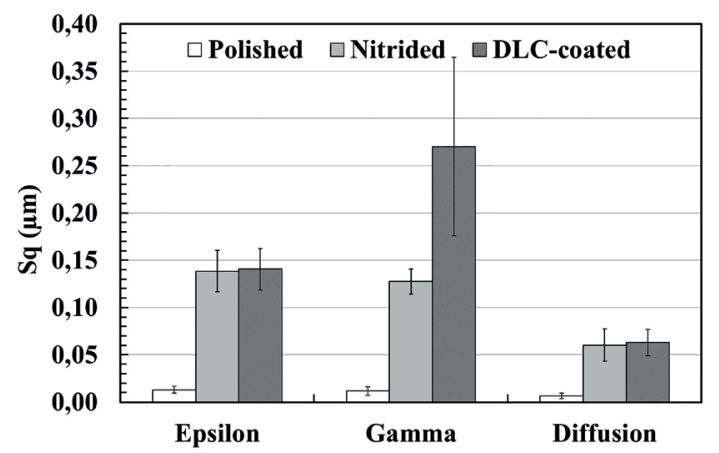

Figure 5: Sq roughness parameter evolution along processing steps: polished surface; nitrided surface; and DLC-coated surface, for each surface condition: $\varepsilon$-phase; $\gamma^{\prime}$-phase ; and diffusion.

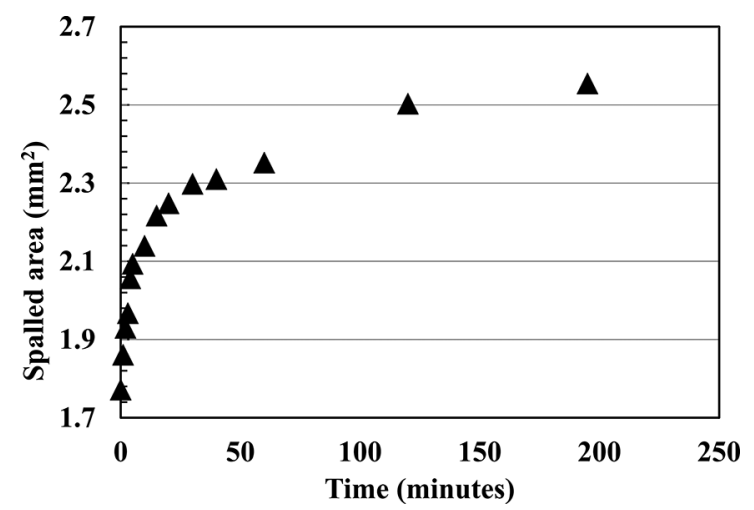

Figure 6: Coating delamination measured by spalled area versus time after Rockwell-C indentation.

To verify that the delamination behaviour was caused by indentation, backscattered SEM images were collected for each type of layer (Figure 9). On the indented $\varepsilon$ layer, circumferential and radial cracks can be observed on the compound layer, which tend to appear during loading and unloading, respectively ${ }^{33}$. Similarly to that on the $\varepsilon$ layer, the delamination on the $\gamma$ ' layer occurred along the perimeter of the indentation; radial cracks occurred on the compound layer, but circumferential cracks could not be observed. Under these conditions, delamination occurred such that small pieces of the coating remained attached to the nitrided surface while remaining surrounded by uncoated areas, revealing the distinct propagation of the delamination. On the indented coated diffusion layer, no cracks were observed, and the border was clear due to the higher deformation sustained under these conditions.

Consequently, adhesion was strongly related to the surface conditions of the films, and the following factors exerted the greatest influence:

- Roughness: Rougher surfaces were rich in peaks and valleys; stress tended to concentrate among these variations in amplitude, and the film tended to crack first $\mathrm{t}^{34}$.

- Layer morphology: Characteristics of the formed layers, including thickness, yield modulus, yield and ultimate tensile strength, affected the stress field during and after indentation. Therefore, different types of cracks and deformed regions caused distinct delamination behaviours.

- Coating homogeneity: The quality of the DLC coating was related to the topography of the nitrided surface. Depending on the characteristics, a homogeneous or heterogeneous coating could be formed, generating different failure patterns.

The behaviour of the coated surfaces during durability testing is shown in Figure 10. The coefficient of friction was followed under each condition until each film ruptured; at that point, an abrupt increase in the measured value was observed. In Figure 10, the coefficient of friction is drawn in black, whereas the stepped force is drawn in light grey; both parameters are plotted versus distance travelled.

The evolution of the coefficient of friction (COF) in the graph clearly shows that each set of conditions exhibited distinct tribological behaviours. The best tribological performance was achieved by the DLC coating over the diffusion layer, exhibiting a durability of $13,000 \mathrm{Nm}$ and the lowest COF (approximately 0.05 ). The coated $\varepsilon$ layer was the second best, exhibiting a durability of approximately $6,000 \mathrm{Nm}$ and an initial COF of 0.125 that smoothly decreased to 0.1 . The worst performance was demonstrated by the coated 'layer; this system failed at the beginning of the test, exhibiting a durability of $600 \mathrm{Nm}$ and the highest COF (0.2).

The durability results and their relationships to the adhesion test results revealed antagonistic behaviour, as shown in

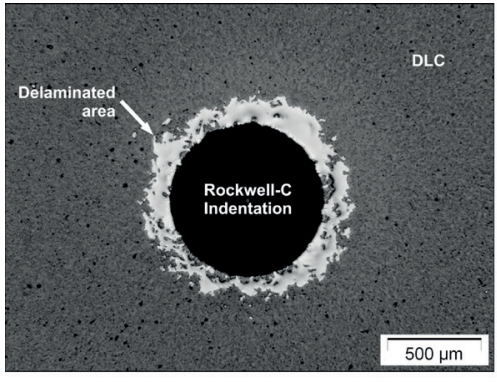

(a)

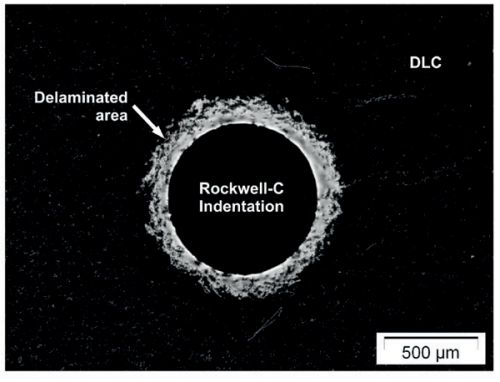

(b)

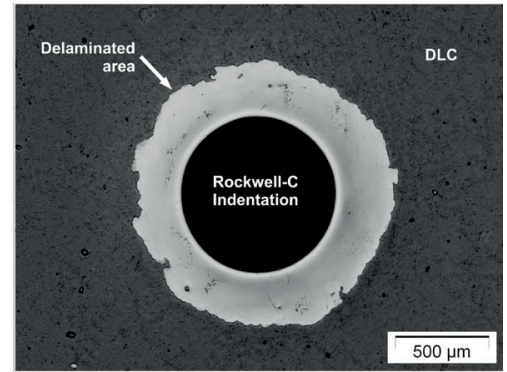

(c)

Figure 7: Top-down micrographs of Rockwell-C indentation assessing delaminated area of: (a) coated $\varepsilon$-phase surface; (b) coated $\gamma^{\prime}-$ phase surface; (c) Coated diffusion surface. 


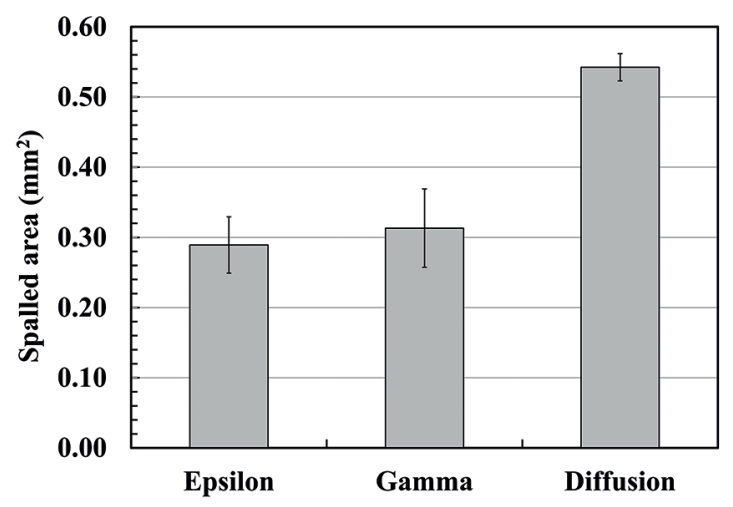

Figure 8: DLC spalled area caused by Rockwell-C indentation on: coated $\varepsilon$-phase, coated $\gamma^{\prime}$-phase, and coated diffusion surfaces.

Figure 11; both variables are presented in the same graphic. Adhesion is expressed as the inverse of the delaminated area. Consequently, the best response for both tests is the upper limit of the graph area; specifically, the durability should be maximised, and the delaminated area should be minimised. However, these attributes are not presented in the figure. Although the diffusion layer exhibited the worst adhesion during the indentation test, it demonstrated the highest durability and the smallest coefficient of friction. However, the DLC over the $\gamma$ ' layer showed the worst tribological behaviour but did not show accentuated delamination, as observed under the $\varepsilon$ conditions.

To understand these results, the wear tracks were analysed; the corresponding SEM images are shown in Figure 12. As demonstrated by the development of the coefficient of friction, the wear tracks were very different. At the end of the tests, when the coefficient of friction rapidly increased, a tribolayer persisted on the $\varepsilon$ layer, with small regions containing the apparent substrate. On the $\gamma$ ' layer, a tribolayer had developed before being removed, revealing the substrate. The visible bands of this layer could be observed at the end of the test. For the diffusion layer, which achieved the longest sliding distance, the film was completely removed, and the interface between the wear track and the coating edge was defined. Small portions under the DLC were also removed due to the higher stresses. In addition, the track width was larger due to the larger normal load.

An analysis of these images and results revealed that the heterogeneous formation of DLC on top of the $\gamma$ ' nitrided layer was quickly removed during the sliding test even though little delamination was produced next to the Rockwell-C indentation. This phenomenon occurred because the indentation was restricted to one point, whereas the sliding tests involved lateral movement. As the counter body slides along the track, the deformation moves, causing the film to fail. A tribolayer is formed but is quickly removed, ending the low friction regime prematurely. In addition, the same delamination mechanism observed at the indentation border was observed along the side marks of the track, as shown in Figures 9 and 12.

The coated $\varepsilon$ layer, which also exhibited a high roughness with the formation of homogeneous DLC, demonstrated a higher durability; at the end of the test, the tribolayer remained in place even though some pieces were removed. Therefore, even when the delamination areas were equivalent, the responses of the $\varepsilon$ and $\gamma$ ' conditions were distinct.

Nevertheless, the behaviour of the coated diffusion layer was special; under these conditions, the greatest extent of delamination occurred when the surface presented the highest durability. To understand this behaviour, the test parameters must be considered. Whereas the indentation test used a $1474 \mathrm{~N}$ load, the load used during the sliding test did not exceed $70 \mathrm{~N}$, meaning that the results were obtained under different stress and deformation regimes.

Clearly, a direct correlation between the adhesion tests using Rockwell-C indentation and the durability tests using the sliding movement of the tribometer cannot be attained because the failure mechanisms may be different, resulting in the distinct crack patterns that could be observed on the $\varepsilon$ and $\gamma$ ' surfaces or in the antagonistic effect on the diffusion surface.

In addition, the coefficient of friction was reduced during the tribometer tests; the $\gamma$ ' conditions were an exception due to the failure observed at the beginning

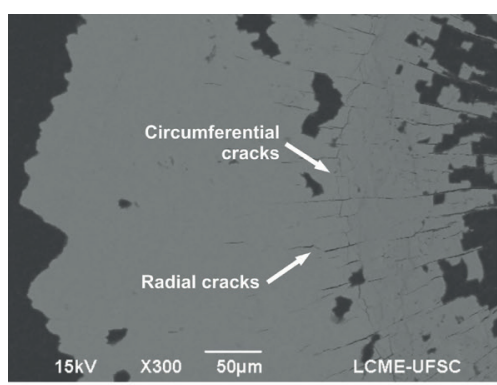

(a)

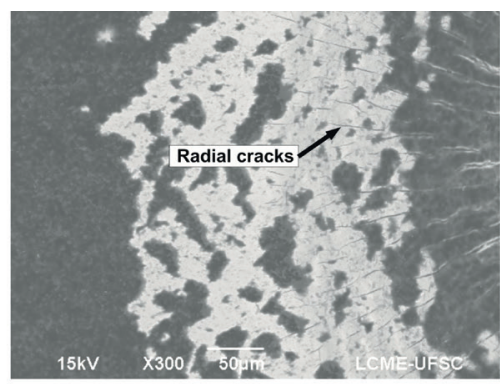

(b)

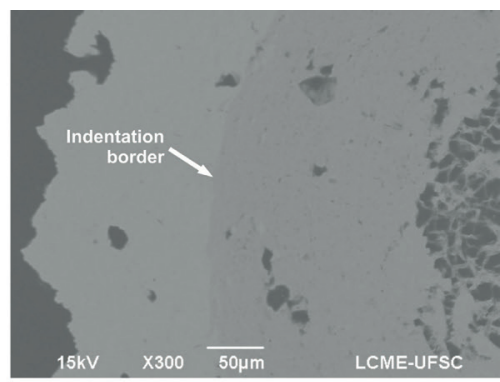

(c)

Figure 9: Top-down SEM images of Rockwell-C indentations on: (a) coated $\varepsilon$-phase surface; (b) coated $\gamma$ '-phase surface; and (c) coated diffusion surface, evidencing failure patterns. 


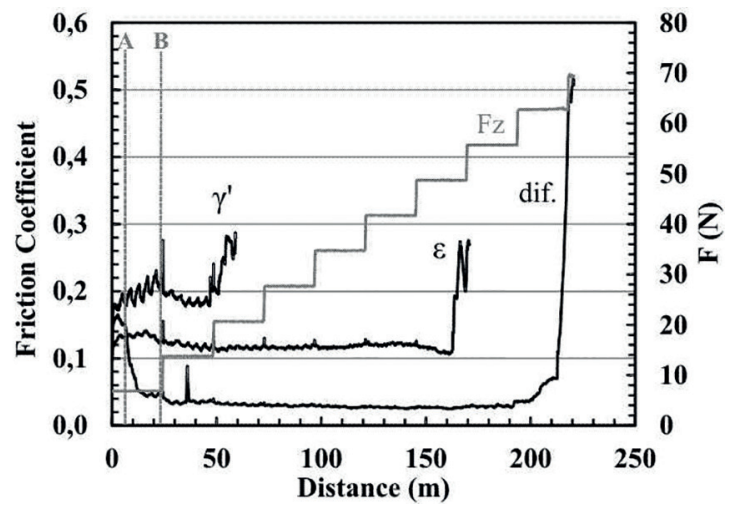

Figure 10: Coating durability of: coated $\varepsilon$-phase surface; coated $\gamma^{\prime}-$ phase surface; and coated diffusion surface, assessed with incremental loading reciprocating sliding test performed in tribometer.

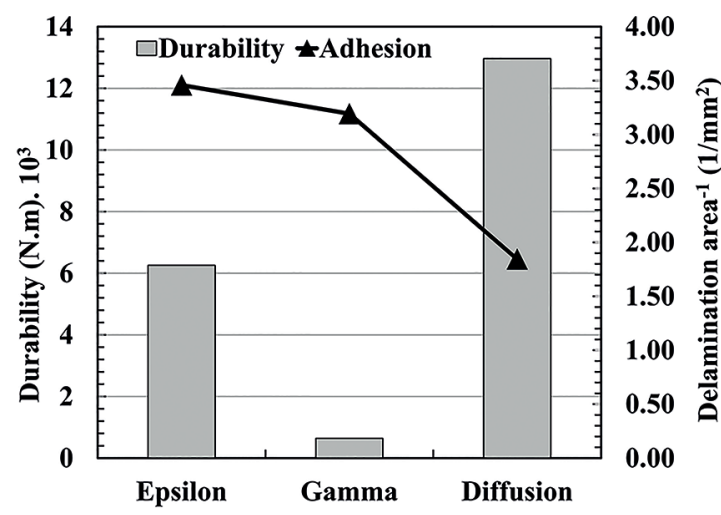

Figure 11: Coating durability and adhesion measured by tribometer durability test and Rockwell-C indentation caused by delamination area of: coated $\varepsilon$-phase surface; coated $\gamma^{\prime}$-phase surface; and coated diffusion surface.

of the test. To analyse this effect, two additional wear tracks were produced on the coated diffusion layer: one interrupted the test at point $\mathrm{A}$ in Figure 10 when the friction was still high, and the other occurred at point $\mathrm{B}$ when the friction stabilised to a lower level. Consequently, all three conditions, specifically the intact coated surface, the high-friction regime and the low-friction regime, could be assessed together. The Sq value reveals that the roughness decreased significantly at the beginning of the test (Figure 13).

SEM images were collected for the two friction regimes, and they are presented in Figure 14, with the wear tracks marked by arrows. During the first stopping point of the test, the friction was high; the roughness was only reduced through surface smoothing, which was almost imperceptible. However, when the test was stopped during the low-friction regime, a tribolayer was observed; although, the roughness level of the tribolayer did not vary, the formation of the layer was the primary reason that the coefficients of friction were reduced. Therefore, from a tribological perspective, the DLC coating produced over these nitrided surfaces required an initial smoothing period before the best operation conditions were reached.

The results show that the topography and the type of nitrided layer used directly affected the performance of the DLC-coating. Topographic and morphologic control proved to be extremely important because the conditions to generate mechanical support also improve roughness and negatively affect the tribological performance of the multifunctional system.

\section{Conclusions}

Roughness was observed to affect the tribological performance of DLC films deposited over nitrided layers. Depending on the processing conditions and resulting nitrided layers, the durability could be enhanced and the coefficient of friction could be reduced.

The best conditions for this system involved depositing the DLC over the nitrided diffusion layer that, after an initial smoothing period, demonstrated the best tribological performance.

A direct comparison between the results of the adhesion tests performed using Rockwell-C indentation and those obtained from durability tests performed in a tribometer is not possible unless stress and deformation fields, as well as other characteristics of the surfaces, are assessed.

DLC coatings can be affected by the formation of a nitrided compound layer; in this case, coating a $\gamma^{\prime}$ layer formed a heterogeneous film.

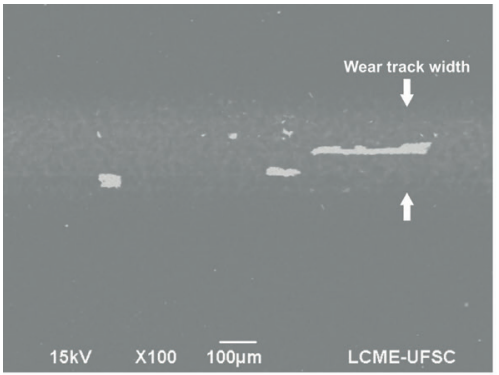

(a)

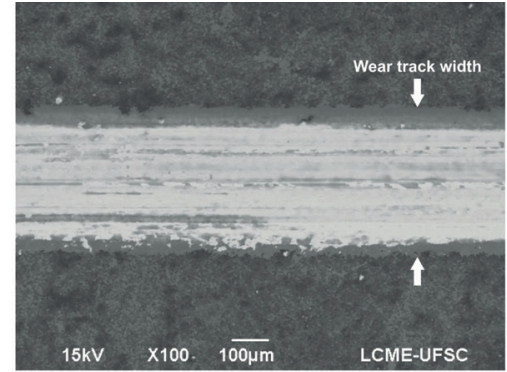

(b)

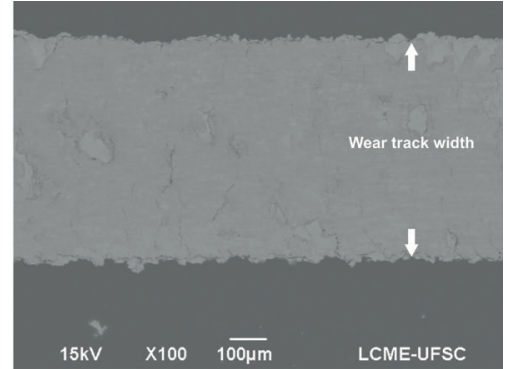

(c)

Figure 12: Top-down SEM micrographs showing wear tracks of: (a) coated $\varepsilon$-phase surface; (b) coated $\gamma^{\prime}$-phase surface; (c) and coated diffusion surface, produced in tribometer durability test. 


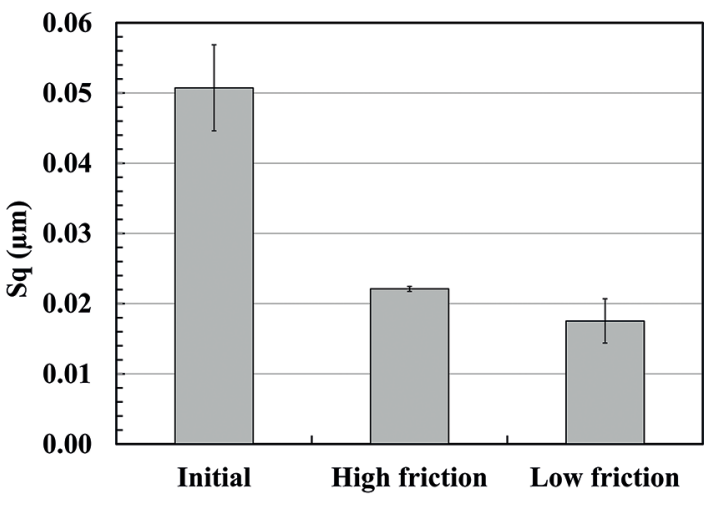

Figure 13: Sq roughness parameter of diffusion layer wear track measured on: the initial intact surface; high-friction regime; and low-friction regime.

The processing conditions used to grow the $\varepsilon$ and $\gamma^{\prime}$ compound layers increased the roughness of the surface by a factor of approximately two relative to that achieved under the conditions used to grow only the diffusion layer.

\section{Acknowledgements}

The authors acknowledge the following Brazilian agencies for funding this research: CNPq, BNDES, CAPES-PROEX and Whirlpool/Embraco.

\section{References}

1. Donnet C, Erdemir A, eds. Tribology of Diamond-Like Carbon Films - Fundamentals and Applications. New York: Springer; 2008. 664 p. doi:10.1007/978-0-387-49891-1.

2. Erdemir A, Eryilmaz OL, Nilufer IB, Fenske GR. Effect of source gas chemistry on tribological performance of diamond-like carbon films. Diamond and Related Materials. 2000;9(3-6):632-637. doi:10.1016/S0925-9635(99)00361-1.

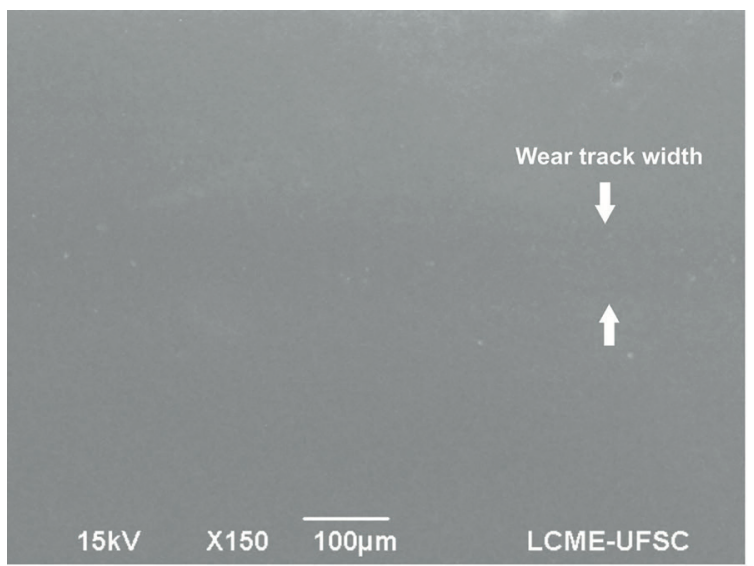

(a)
3. Erdemir A, Eryilmaz OL, Fenske G. Synthesis of diamondlike carbon films with superlow friction and wear properties. Journal of Vacuum Science \& Technology A. 2000;18(4):1987-1992. doi:10.1116/1.582459.

4. Grill A. Tribology of diamondlike carbon and related materials: an updated review. Surface and Coatings Technology. 1997;9495:507-513. doi:10.1016/S0257-8972(97)00458-1.

5. Buršíková V, Navrátil V, Zajíčková L, Janča J. Temperature dependence of mechanical properties of DLC/Si protective coatings prepared by PECVD. Materials Science and Engineering: A 2002;324(1-2):251-254. doi:10.1016/S0921-5093(01)01320-X.

6. Dorner A, Schürer C, Reisel G, Irmer G, Seidel O, Müller E. Diamond-like carbon-coated Ti6Al4V: influence of the coating thickness on the structure and the abrasive wear resistance. Wear. 2001;249(5-6):489-497. doi:10.1016/S0043-1648(01)00587-7.

7. Horiuchi T, Yoshida K, Okuda T, Kano M, Kumagai M, Suzuki T. Session 01: DLC coatings OA 01 P2009-245 evaluation of adhesion strength and wear resistance of DLC films. Surface and Coatings Technology. 2010;205(Suppl 1):S188-S195. doi:10.1016/j.surfcoat.2010.07.068.

8. Dalibon EL, Charadia R, Cabo A, Trava-Airoldi V, Brühl SP. Evaluation of the mechanical behaviour of a DLC film on plasma nitrided AISI 420 with different surface finishing. Surface and Coatings Technology. 2013;235:735-740. doi:10.1016/j.surfcoat.2013.08.059.

9. Rechberger J, Brunner P, Dubach R. High performance cutting tools with a solid lubricant physically vapour- deposited coating. Surface and Coatings Technology. 1993;62(1-3):393-398.

10. Pye D. Practical nitriding and ferritic nitrocarburizing. Materials Park: ASM International; 2003.

11. De Mello JDB, Binder C, Binder R, Klein AN. Effect of nature of nitride phases on microabrasion of plasma nitrided sintered iron. Tribology - Materials, Surfaces \& Interfaces. 2010;4(4):191196. doi:10.1179/1751584X10Y.0000000001.

12. Campagna V, Bowers R, Northwood DO, Sun XC, Bauerle P. Comparison of carbonitriding and nitrocarburising on size and shape distortion of plain carbon SAE 1010 steel. Surface Engineering. 2010;27(2):86-91. doi:10.1179/02670841 0X12687356948553.

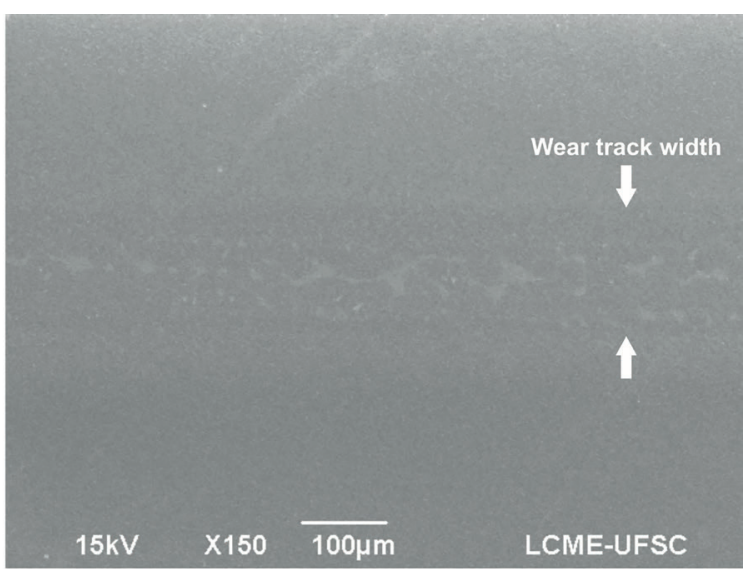

(b)

Figure 14: Top-down SEM micrographs of coated diffusion surface showing wear tracks on: (a) High friction regime; and (b) Low friction regime, indicated by tribometer durability test. 
13. Christiansen T, Somers MAJ. Controlled dissolution of colossal quantities of nitrogen in stainless steel. Metallurgical and Materials Transactions A. 2006;37(3):675-682. doi:10.1007/ s11661-006-0039-5.

14. Funatani K. Low-temperature salt bath nitriding of steels. Metal Science and Heat Treatment. 2004;46(7):277-281. doi:10.1023/B:MSAT.0000048834.48163.2e.

15. Wu D, Kahn H, Dalton JC, Michal GM, Ernst F, Heuer AH. Orientation dependence of nitrogen supersaturation in austenitic stainless steel during low-temperature gas-phase nitriding. Acta Materialia. 2014;79:339-350. doi:10.1016/j.actamat.2014.07.007.

16. Pinedo CE, Monteiro WA. Surface hardening by plasma nitriding on high chromium alloy steel. Journal of Materials Science Letters. 2001;20(2):147-150.

17. Meletis EI, Erdemir A, Fenske GR. Tribological characteristics of DLC films and duplex plasma nitriding/DLC coating treatments. Surface and Coatings Technology. 1995;73(12):39-45. doi:10.1016/0257-8972(94)02375-1.

18. Michler T, Grischke M, Traus I, Bewilogua K, Dimigen H. DLC Films deposited by bipolar pulsed DC PACVD. Diamond and Related Materials. 1998;7(2-5):459-462. doi:10.1016/S0925-9635(97)00236-7.

19. Dalibon EL, Trava-Airoldi V, Pereira LA, Cabo A, Brühl SP. Wear resistance of nitrided and DLC coated PH stainless steel. Surface and Coatings Technology. 2013;255:22-27. doi:10.1016/j. surfcoat.2013.11.004.

20. ASM International. ASM Handbook Vol 4: Heat-treating. Materials Park: ASM International; 1991.

21. Klein AN, Cardoso RP, Pavanati HC, Binder C, Maliska AM, Hammes G, et al. DC Plasma Technology Applied to Powder Metallurgy: an Overview. Plasma Science and Technology. 2013;15(1):70-81. doi:10.1088/1009-0630/15/1/12.

22. Jeong BY, Kim MH. Effects of pulse frequency and temperature on the nitride layer and surface characteristics of plasma nitrided stainless steel. Surface and Coatings Technology. 2001;137(23):249-254. doi:10.1016/S0257-8972(00)01095-1.

23. Karakan M, Alsaran A, Çelik A. Effects of various gas mixtures on plasma nitriding behavior of AISI 5140 steel. Materials Characterization. 2002;49(3):241-246.

24. Masuko M, Kudo T, Suzuki A. Effect of surface roughening of substrate steel on the improvement of delamination strength and tribological behavior of hydrogenated amorphous carbon coating under lubricated conditions. Tribology Letters. 2013;51(2):181190. doi:10.1007/s11249-013-0106-1.
25. Singh GP, Alphonsa J, Barhai PK, Rayjada PA, Raole PM, Mukherjee S. Effect of surface roughness on the properties of the layer formed on AISI 304 stainless steel after plasma nitriding. Surface and Coatings Technology. 2006;200(20-21):5807-5811. doi:10.1016/j.surfcoat.2005.08.149.

26. Vidakis N, Antoniadis A, Bilalis N. The VDI 3198 indentation test evaluation of a reliable qualitative control for layered compounds. Journal of Materials Processing Technology. 2003;143-144:481-485. doi:10.1016/S0924-0136(03)00300-5.

27. Heinke W, Leyland A, Matthews A, Berg G, Friedrich C, Broszeit E. Evaluation of PVD nitride coatings, using impact, scratch and Rockwell-C adhesion tests. Thin Solid Films. 1995;270(12):431-438. doi:10.1016/0040-6090(95)06934-8.

28. Ikeyama M, Nakao S, Miyagawa Y, Miyagawa S. Effects of Si content in DLC films on their friction and wear properties. Surface and Coatings Technology. 2005;191(1):38-42. doi:10.1016/j. surfcoat.2004.08.075.

29. Nakanishi K, Mori H, Tachikawa H, Itou K, Fujioka M, Funaki $\mathrm{Y}$. Investigation of DLC-Si coatings in large-scale production using DC-PACVD equipment. Surface \& Coatings Technology. 2006;200(14-15):4277-4281. doi:10.1016/j.surfcoat.2005.02.167.

30. De Mello JDB, Binder R. A methodology to determine surface durability in multifunctional coatings applied to soft substrates. Tribology International. 2006;39(8):769-773. doi:10.1016/j. triboint.2005.07.015.

31. Mason RS, Pichilingi M. Sputtering in a glow discharge ion source-pressure dependence: theory and experiment. Journal of Physics D: Applied Physics. 1999;27(11):2363-2371. doi:10.1088/0022-3727/27/11/017.

32. Pérez R EA, Souza RM. Numerical and experimental analyses on the contact stresses developed during single and successive indentations of coated systems. Surface and Coatings Technology. 2004;188-189:572-580. doi:10.1016/j. surfcoat.2004.07.014.

33. Pachler T, Souza RM, Tschiptschin AP. Finite element analysis of peak stresses developed during indentation of ceramic coated steels. Surface and Coatings Technology. 2007;202(4-7):10981102. doi:10.1016/j.surfcoat.2007.07.041.

34. Strafford KN, Subramanian C, Wilks TP. Properties and characteristics of advanced tribological surface coatings and the assessment of quality-for-performance for enhanced manufacturing efficiency. Journal of Materials Processing Technology. 1993;38(1-2):431448. doi:10.1016/0924-0136(93)90215-R 